\title{
Los TEXTOS INSCRITOS EN LA FonCALAdA DE OvIEDO
}

\author{
José Antonio VAldÉs Gallego ${ }^{1}$ \\ Instituto Mata Jove de Gijón
}

Recibido: 15 de noviembre de 2017

Aceptado: 18 de diciembre de 2017

\begin{abstract}
Resumen
La Foncalada de Oviedo es una fuente monumental, datada generalmente en el siglo IX, durante el período del reino asturiano (718-910). En la fachada del lado este, donde se abre un arco de medio punto, se grabaron algunas inscripciones latinas. Era conocido el contenido de las situadas sobre el arco. Son similares a algunos epígrafes regios de la época. Del texto de las demás solamente se conservan pequeños fragmentos. En este artículo ofrecemos una reconstrucción, lograda gracias a haberse localizado el modelo en que se basan: una oración de santificación del agua, empleada, aunque no exclusivamente, en el ritual hispánico, y contenida en los Libri Ordinum.
\end{abstract}

\section{Palabras clave}

Foncalada; epigrafía medieval; latín medieval; liturgia hispánica; reino de Asturias.

\begin{abstract}
The Foncalada of Oviedo is a monumental fountain commonly dated in the $9^{\text {th }}$ century, at the time of the Asturian Kingdom (718-910). On the façade of the east side, where a semicircular arch opens, some Latin inscriptions were engraved. The content of those situated on the arch is well-known, since they are similar to some royal epigraphs of the period, while only small text fragments have been preserved from the rest of inscriptions. In this work we offer a reconstruction of the latter, based on a finding that what we consider the model or source used for the creation of these epigraphs: a prayer form for the sanctification of water, used, though not exclusively, in the Hispanic rite, and contained in the Libri Ordinum.
\end{abstract}

\section{Keywords}

Foncalada; Medieval epigraphy; Medieval Latin; Hispanic rite; Asturian Kingdom.

\section{Résumé}

La Foncalada d'Oviedo est une fontaine monumentale que l'on date généralement du IX ${ }^{\mathrm{e}}$ siècle, à l'époque du Royaume asturien (718-910). Sur la façade est, où s'ouvre un arc en plein cintre, quelques inscriptions latines ont été gravées. On connaissait la teneur de celles qui sont situées au-dessus de l'arc. Elles sont similaires à certaines inscriptions royales de l'époque. On ne conserve que des fragments des autres textes. Dans cet article, on proposera une reconstruction, obtenue grâce à la découverte de la source qui a inspiré ces inscriptions: une prière de sanctification de l'eau, utilisée, mais pas exclusivement, dans le rituel hispanique et contenue dans les Libri Ordinum.

\section{Mots clés}

Foncalada; Épigraphie médiévale; Latin médiéval; Liturgie Hispanique; Royaume des Asturies.

1 Correo electrónico: jantoniovg@educastur.org. ORCiD: https://orcid.org/0000-0002-4046-4905. 


\section{Introducción}

Al mencionar la Foncalada se destaca su singularidad como único edificio civil conservado del reino de Asturias. La crítica actual tiende a situarla en el reinado de Alfonso $\mathrm{II}^{2}$, frente a la atribución tradicional a Alfonso III, y más recientemente se ha conjeturado incluso un origen romano ${ }^{3}$. Las excavaciones arqueológicas de los años noventa del siglo pasado exhumaron parte del estanque y del canal de la edificación, y han permitido que nos hagamos una idea de su antigua monumentalidad ${ }^{4}$.

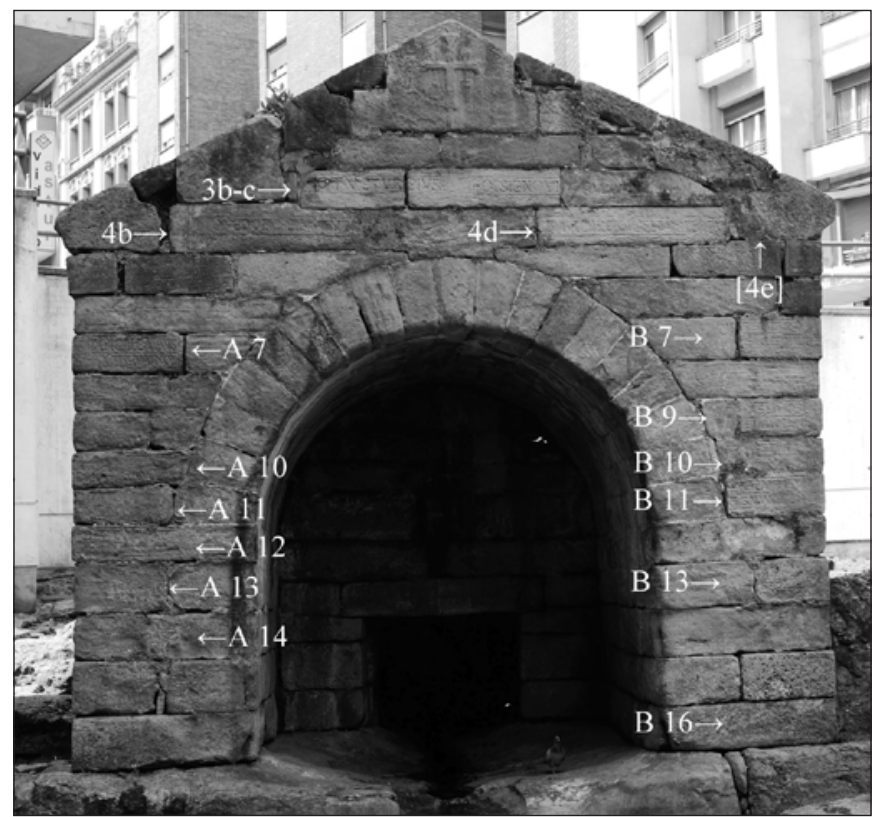

Fachada este del edículo. Se señala la situación de los sillares en que hemos leído caracteres.

Pero de lo que vamos a tratar en estas páginas es del texto de los epígrafes grabados en la fachada este del edículo de la fuente ${ }^{5}$. Por la sustitución de algunos sillares y el

2 Con argumentos arquitectónicos, escultóricos y paleográficos: GARCía de CASTRo VALDÉs, Arqueología cristiana ..., pp. 92 y 497; Ríos GonzÁlez, "La fuente de Foncalada: paralelos...", pp. 268-269. Ambos en "El origen de Oviedo", p. 99.

3 Debido al hallazgo en Oviedo, en 2008, de otra, datada en época tardorromana (la llamada fuente de La Rúa). Un resumen sobre la cuestión y bibliografía en García De Castro Valdés y Ríos GonzÁlez, "El origen de Oviedo", pp. 58 y 99, que son más escépticos al respecto.

4 Fotografía y planta de la excavación en Estrada GARCía y Ríos GonZÁlez, "Excavaciones arqueológicas en la plaza de Foncalada...", pp. 138-139. Reconstrucción de Borge Cordovilla, "La Fuente de Foncalada (Oviedo)...", pp. 165-168. Una recreación virtual del mismo autor en "La fuente de Foncalada", http://www. mirabiliaovetensia.com/Fuente_Foncalada.html.

5 No se ha observado texto en las demás fachadas del templete. 
desgaste de otros, la mayoría es ilegible. "Se descubren además en este monumento notable otra porción de leyendas en muchas piedras de los ángulos del frente principal. Si fuera posible su lectura, no dejaría de prestar algún servicio a la historia"6.

\section{Fragmentos descifrados}

A continuación, recopilaremos los restos de epígrafes que pueden distinguirse en la fachada este del edículo. La reconstrucción quedará para el apartado cuarto. Con el fin de simplificar las citas, hemos establecido una numeración por hiladas, comenzando por el hastial. Desde la altura del arco, además, distinguiremos si se trata de sillares del lado de la jamba sur (izquierda del observador), que denominaremos A, o de la norte (derecha), B. Se han reconstruido sin dificultad las inscripciones que se encuentran entre el hastial y el arco, por su relativo buen estado de conservación y su convergencia con otras contemporáneas. En cada una de las hiladas tercera y cuarta de sillares se dispuso una sola línea de texto, inscrita en cartelas ${ }^{7}$. Hemos calculado unos 6 centímetros de altura de las letras. Leemos:

\section{3b-c: .O TVETVR PIVS HOC SIGNO VI}

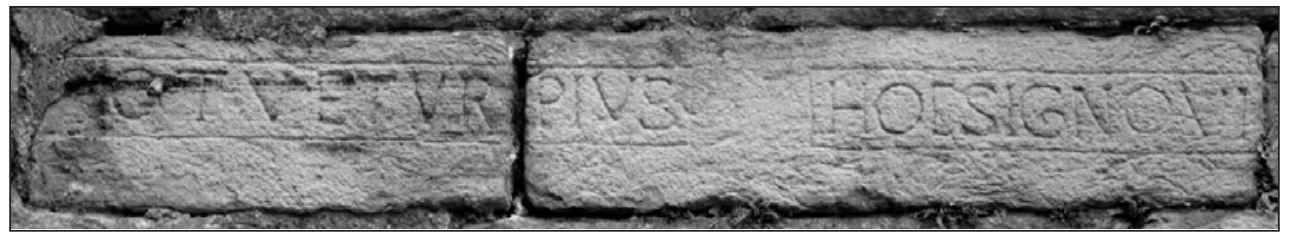

\section{4 b: ... .ONE DOMINE IN FONTE}

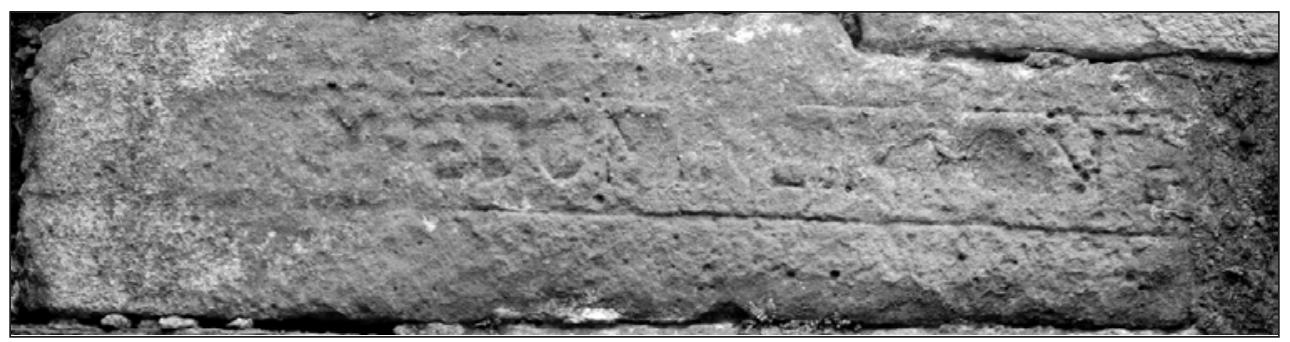

6 Miguel Vigil, Asturias monumental..., pp. 183-184. Se manifestaba en el mismo sentido De Selgas, Monumentos ovetenses del siglo IX, p. 113: "muchos sillares han desaparecido, y sustituidos [sic], y en todos los que quedan se ven huellas de leyendas ininteligibles, y que si se conservaran darían alguna luz para ilustrar la historia de la ciudad". Redunda en el valor de las inscripciones perdidas para la interpretación del monumento uno de sus máximos conocedores, el mencionado Ríos GonZÁLEZ: "Excavación arqueológica en la Foncalada: 1991-1995”, p. 186.

7 Algunas piedras no son ya las originales: por lo menos se efectuó una reconstrucción en 1848, y además hubo otra reforma de la fuente en 1959-1961 (GARCÍA DE CASTRO VALDÉs, Arqueología cristiana ..., p. 496). Una copia del epígrafe que conmemoraba la reparación del XIX, en Miguel VIGIL, Asturias monumental..., vol. 2, lámina K 3. 


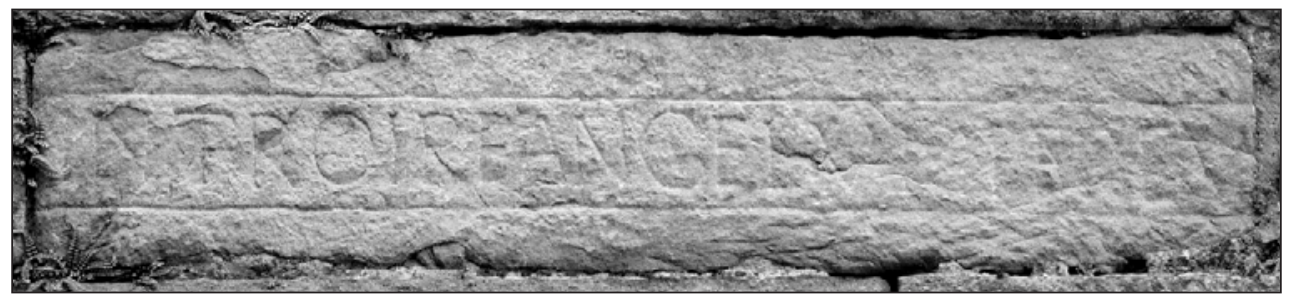

Lecturas de los editores previos ${ }^{9}$ :

\section{O ] NO García de Castro $\| 4$ ONE ] NE Diego, Vigil; E García de Castro | PERCVTIENTEM ] -TIENTEM restituerunt Diego, Vigil.}

Mayor complicación encerraba el texto inciso en los laterales del arco, por el deterioro o la sustitución de las piedras.

Preferentemente en los sillares exteriores ${ }^{10}$ de las jambas del arco, y parece que a partir de la hilada quinta ${ }^{11}$, se grabaron dos o tres líneas de texto ${ }^{12}$. Se encuentran inscritas en pautas, reconocibles en buena parte de las piedras, aun cuando el texto se haya perdido $^{13}$. Hay unos márgenes exteriores que se prolongan verticalmente en cada jamba. En A 7, como en las hiladas tercera y cuarta, la altura de las letras está en torno a 6 cms. $^{14}$, pero en el sillar ya se escriben dos líneas de texto; en A 10, sobre 5 cms.; en A 12-14, unos 4 cms. Las letras de B 7 y B 9 tienen 5 cms. de altura media; B 11, 4; B 13 y B $16,2,8 \mathrm{cms}$.

\footnotetext{
8 El fragmento -TIENTEM, grabado en el remate de la cornisa norte original, no se encuentra en la fuente: se halló en la excavación arqueológica. Descripción y dibujo en Ríos González, Estrada García y Chao Arana, "La fuente de Foncalada (Oviedo)", pp. 412-413. Una fotografía en García de CAstro Valdés, Arqueología cristiana..., p. 629.

9 Diego Santos, Inscripciones medievales de Asturias, p. 105; García de Castro Valdés, Arqueología cristiana ..., p. 91; Miguel Vigil, Asturias monumental..., vol. 1, p. 183; vol. 2, lám. K 2. Incluimos aquí solamente sus lecturas: las propuestas de reconstrucción son unánimes con la que desarrollaremos en el apartado 4.1, con la salvedad de las observaciones que figurarán en las notas 32 y 33.

10 Cuando son cortos, el texto puede invadir la piedra contigua, como en B 7, 9, 13.

11 Volveremos sobre la cuestión en el apartado 4.2.

12 Hay tres en A 13 y 14, y creemos que las hubo en B 12, 13, 14 y 16.

13 La pauta puede extenderse más allá del campo escrito. En el sillar exterior de A 6 incluso parece continuar por el lado sur del templete, sin que distingamos texto alguno.

14 La forma de las letras difiere con respecto a las grabadas en las hiladas 3 y 4 . Compárense, por ejemplo, la $C$ y la $O$ en las primeras con las de A 7, el sillar con las letras más nítidas. Pero no nos corresponde abordar este asunto.
} 
A los lados del arco, el consenso de los editores $\operatorname{previos}^{15}$ se limita a $X p($ ist $)$ i, en A 7; un estudioso $\mathrm{u}$ otro ${ }^{16}$ reconstruye palabras completas en la jamba norte (B), a veces sin deslindarlas, porque el texto fue grabado en escritura continua, lo que dificultaba su interpretación: tu rursu(m), B 7, globum, B 9, salus, B 11, abdita, B 13. Además, no se conocía el contenido del epígrafe, lo que complicaba el desciframiento y la reconstrucción. El hallazgo de la fuente textual, a la que nos referiremos en el apartado siguiente, y el examen de fotos de los sillares nos han permitido localizar letras no identificadas hasta ahora, e igualmente delimitar con seguridad palabras o partes de ellas. Creemos haber logrado un avance apreciable ${ }^{17}$. Los fragmentos conservados presentan pocas abreviaturas ${ }^{18}$ y ligaturas de letras ${ }^{19}$.

A (lado de la jamba sur)

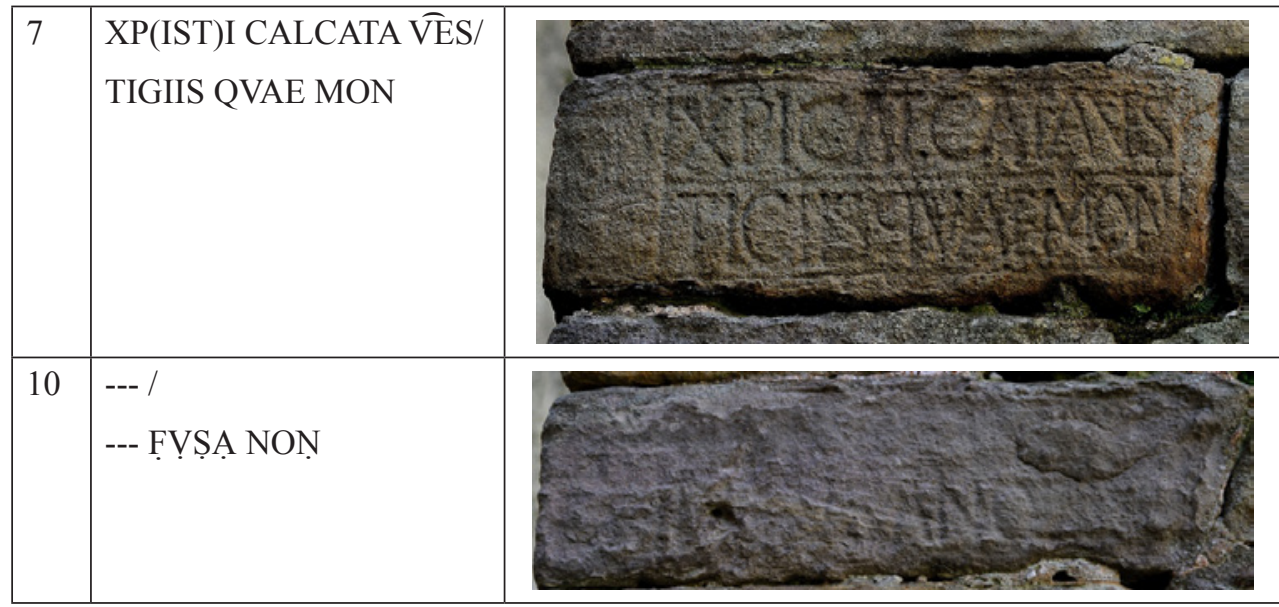

15 Diego Santos, Inscripciones medievales de Asturias, pp. 106-107: sillares A 7 y B 7, 9, 11; el más atinado, García de Castro Valdés, Arqueología cristiana ..., p. 91: los citados, más A 12, 14 y B 13; Miguel Vigil, Asturias monumental..., vol. 2, lám. K 2: letras, o restos, en A 7, 12, 13, 14; B 7, 8 (trazos informes), 9, 10, 11, 13. En época de Vigil, las piedras estaban menos desgastadas; en algún caso, gracias a su celo, podremos situar en su sillar correspondiente fragmentos de texto. Por otro lado, las hiladas 15-16 no eran visibles entonces.

16 Véanse en el aparato crítico las lecturas divergentes de los editores previos. Vigil procuró dibujar los muñones de letras apenas conservadas, que transcribimos en lo posible.

17 Seguramente podrá descifrar más caracteres alguien con medios técnicos superiores, pericia para utilizarlos y mejor vista. Agradezco a Juan Asensio Martín que se haya prestado a examinar mis lecturas de los fragmentos.

18 Con el símbolo general de abreviatura. Son visibles $\overline{X P I}$ (A 7) y $R V R S \bar{V}$ (B 7).

19 En 4 izquierda (entre el hastial y el arco), de $\widehat{T E}$; en A 7, de $\widehat{V E}$. 


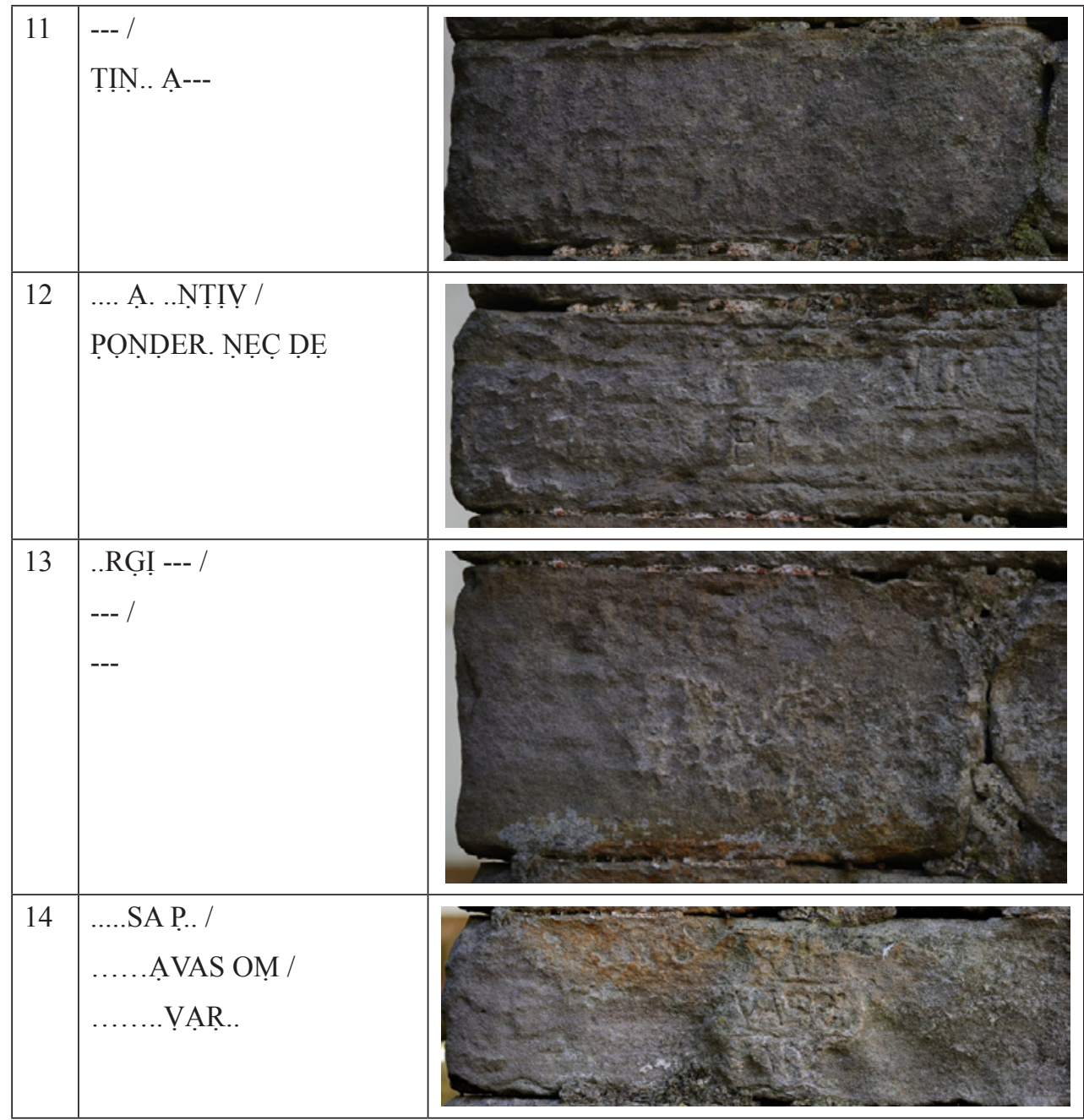

B (lado de la jamba norte)

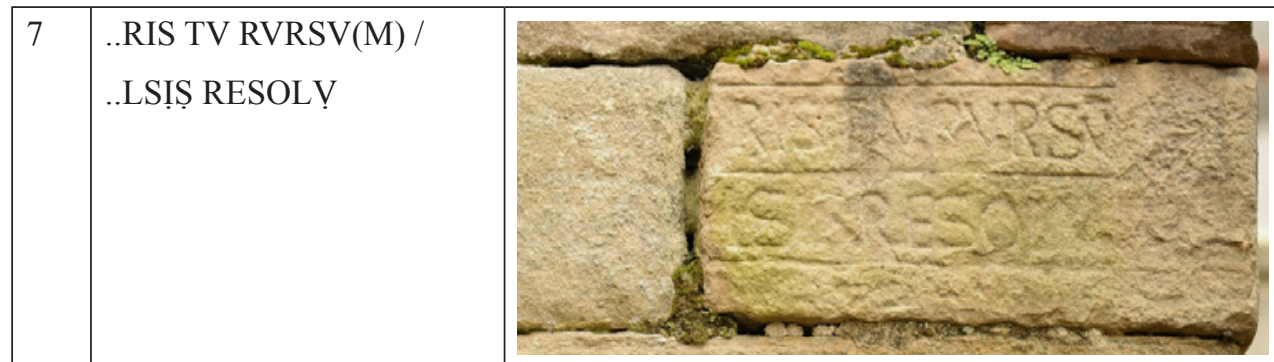




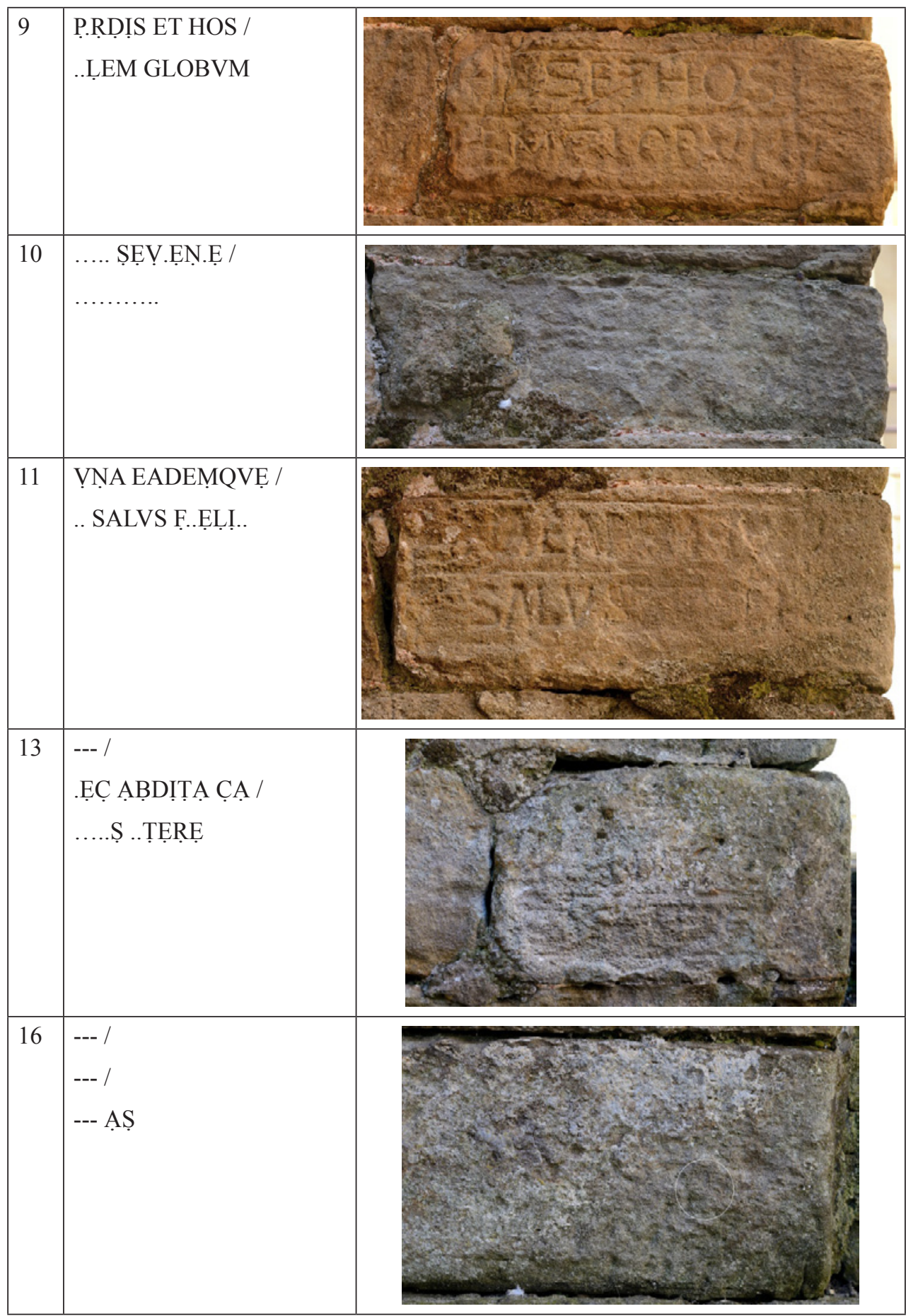


A 7 CALCATA VES- ] CVIQ LAVS Diego; CMC.A.S. García de Castro; CMCATAMS Vigil | -TIGIIS ] P.OS Diego; TIGIS García de Castro; CIS Vigil | QVAE ] QVAM Diego; QVA. García de Castro | MON ] DN Diego; VOVI Vigil $\| 10$ FVSA NON ] om. cett. edd. \|| 11 TIN.. A ] om. Diego, García de Castro; MIPSAГ Vigil \|| 12 ....A. ..NTIV ] om. Diego, García de Castro; S... TE Vigil | PONDER. ] om. Diego, García de Castro; IP... ЕГ Vigil | NEC ] om. cett. edd. | DE ] SS Vigil || 13 RGI ] om. cett. edd.| SC recte legit Vigil $\| 14$ SA P ] om. Diego; SA García de Castro; VSAME Vigil | AVAS OM ] VASQ García de Castro, Vigil | VAR ] om. Diego; AR García de Castro; AIII Vigil. B 7 RIS TV RVRSVM ] $\uparrow[$ C]RISTVM Diego | LSIS ] ES Diego; IS García de Castro; LS Vigil | RESOLV ] REEOLV Vigil \| 9 P.RDIS ] D.S García de Castro | ET ] FE Vigil | LEM ] M Diego; EM García de Castro | GLOBVM ] C EORVM Diego; IC $\Gamma$ S Vigil || 10 SEV. EN.E ] om. Diego, García de Castro; E Vigil $\| 11$ VNA EADEMQVE ] om. Diego; A EADEQV García de Castro; IEIFFQV Vigil | SALVS ] SALVE Vigil | F..ELI.. ] om. Diego, García de Castro; HI Vigil \|| 13 EC ABDITA CA ] om. Diego, García de Castro; V' ABDIГA Vigil | S ..TERE ] om. cett. edd. $\| 16$ AS ] om. cett. edd.

\section{Identificación de las fuentes literarias}

Tradicionalmente, el texto de la tercera hilada, hoc signo... inimicus, se ha tenido por inspirado en la leyenda del lábaro constantiniano in hoc signo uinces ${ }^{20}$, aunque en realidad esa fuente no recoge la primera mitad (hoc signo... pius).

Ha sido identificado con más precisión el origen del epígrafe de la cuarta hilada, una antífona de la liturgia hispánica ${ }^{21}$ adaptada al tipo de monumento ${ }^{22}$.

Las dos composiciones se encuentran en obras regias del período asturiano ${ }^{23}$.

\footnotetext{
20 Es reciente el trabajo de Martín Barba, "La Cruz de Oviedo", pp. 27-50. Recuerda las interpretaciones del lema (asociado a la cruz), estrictamente bélica contra el Islam o escatológica contra Satanás, por la que se inclina, García de Castro Valdés, "La Cruz de la Victoria de la Cámara Santa ...", Codex Aquilarensis, 32 (2016), pp. 31-32.

21 Ya MenÉndez Pidal, "El lábaro primitivo de la Reconquista...", p. 22, veía la derivación del Liber Ordinum. García de CAstro Valdés, Arqueología cristiana..., p. 89, añade el Antifonario de León. Véase también, de este autor, "Notas sobre teología política en el Reino de Asturias...", pp. 152-153. La edición de la antífona, respectivamente en JANINI, Liber Ordinum Episcopal, p. 77, y Brou-VIVES, Antifonario visigótico mozárabe de la catedral de León, p. 427. La antífona halló su inspiración en textos bíblicos: el ángel golpeador es mencionado explícitamente en II Sm 24,16-17 (Dios destruye al pueblo de Israel, y David le ruega que abata el castigo sobre él y sobre la casa de su padre); el signo en los dinteles, en Ex 12,13,21-23. Seguimos la versión de la Vulgata llamada de Stuttgart.

22 La versión conocida de la antífona se refiere primero a "puertas" y luego a "casas": signum salutis pone, Domine, in ianuis istis, ut non permittas introire angelum percutientem. In domibus in quibus uos habitatis ponam signum meum, dicit Dominus, et protegam uos, et non erit in uobis plaga nocens.

${ }_{23}$ Hoc signo..., en las cruces de los Ángeles (la más antigua, de 808), de Santiago de Compostela (874) y de la Victoria (908), con transcripciones en García de CASTRo Valdés, ed., Signum Salutis..., pp. 120-127, 147-151,
} 
Para reconocer la obra que se copió en el resto de la fachada ha sido fundamental haber descifrado correctamente el texto de A 7: Xp(ist)i calcata uestigiis quae mon-. El comienzo, "hollada por los pasos de Cristo", parecía una alusión al milagro que obró Jesucristo al caminar sobre las aguas (Mt 14,25-51; Mc 6,48-50; Io 6,19-21). El participio debía concertar con aqua o un sinónimo. Podía tratarse, como así ha sido, de una oración sobre el agua, que figuraba por lo menos en dos obras de la liturgia hispánica, los Libri Ordinum (Episcopalis y Sacerdotalis) ${ }^{24}$. Consideramos que la fuente directa del texto prácticamente perdido de la Foncalada es el Liber Ordinum Episcopalis, también inspirador, según acabamos de ver, del epígrafe de la hilada cuarta $\mathrm{y}$, sin duda, a disposición en la capital del reino ${ }^{25}$. No obstante, y sin que sean materia de este trabajo los vínculos entre los ritos, hay que reseñar que la oración no es exclusiva de los Ordines hispánicos ${ }^{26}$ : he podido acceder a versiones en el ritual ambrosiano, en el Liber sacramentorum, atribuido a san Gregorio Magno, que publicó Migne, y está igualmente incluida en el Pontifical romano ${ }^{27}$. También la edita Edmond Martène en su repertorio ${ }^{28}$.

La oración, que en la Foncalada no se grabó completa, se denomina en los libros españoles simplemente oratio (en el Sacerdotal) o, más específicamente, benedictio fontis (en el Episcopal). Está incluida en un ritual de bautismo ${ }^{29}$.

156-165; también se leía en una piedra de las torres de Catoira (Pontevedra), que desde Ángel del Castillo y Luis Menéndez Pidal ha sido situada en la época del reino asturiano (Menéndez PidAL, "Influencias y expansión de la arquitectura prerrománica asturiana...", pp. 92-96. Signum salutis... en la lápida de Alfonso III llamada "del palacio" o "de la fortaleza", de 875 (transcripción en GARCíA DE CASTRO VALDÉs, Arqueología cristiana ..., pp. 8889). Hoc signo... y signum salutis... juntas, en la llamada inscripción "de las puertas" (edición, op. cit., 121-122, con referencias a otros epígrafes similares). Omitimos aquí muestras de la pervivencia de estas composiciones en tiempos posteriores o en obras que no obedezcan con probabilidad al impulso regio.

24 La oración, en JANINI, Liber Ordinum Episcopal, p. 82; Liber Ordinum Sacerdotal, pp. 54-55. Los rituales habían sido editados de modo unitario por Férotin, Le Liber Ordinum ... La oración, en la p. 30.

25 Los Ordines son libros citados con relativa frecuencia en los diplomas. DíAz y Díaz contabilizaba 46 menciones en el territorio asturleonés entre los siglos VIII y X (Códices visigóticos en la monarquía leonesa, p. 179). Alfonso III llega a dotar San Adriano de Tuñón con libros ecclesiasticos, entre los que figura uno Ordinum. Edición del documento, de Rodríguez Díaz, El libro de la "Regla Colorada...", p. 300.

26 Ya señalaba Férotin, Le Liber Ordinum ..., p. 30, nota 4, la existencia de versiones paralelas de la oración en el Pontifical romano y en el rito ambrosiano. No he podido localizar la oración en todas las obras que cita JANINI (Liber Ordinum Episcopal, p. 400).

27 Mercati, Antiche reliquie liturgiche ambrosiane e romane..., pp. 25-26 (una parte de la oración figura también en los comentarios ambrosianos al Evangelio de san Lucas: Ambrosin, Expositio Evangelii secundum Lucam, col. 1815); Gregori MAGNI, Liber sacramentorum, cols. 153-154 (Migne sigue en su edición la de Hugo Ménard); Pontificale Romanum Clementis VIII..., pp. 319-320 (es la edición de 1595: otras más modernas de este Pontifical contienen errores en el texto que nos ocupa).

28 Martene, De antiquis ecclesiae ritibus libri, pp. 291-292. Informa en las páginas 284 y 291 de que se trata de una bendición alternativa para un ritual de dedicación de iglesias; los textos estaban incluidos en un manuscrito del arzobispo Halinardo de Lyón.

29 La segunda obra conserva el rótulo: ordo babtismi celebrandus quolibet tempore (transcripción de JANINI, Liber Ordinum Episcopal, p. 80). 


\section{Reconstrucción del conjunto epigráfico}

\subsection{Entre el hastial y el arco}

Bajo la cruz $(\mathrm{A} \uparrow \omega)$, se restituyen los dos epígrafes conocidos, por lo que no aportamos ninguna novedad ${ }^{30}$. El texto corre a lo largo de la hilada en una sola línea. El número máximo ${ }^{31}$ de letras que abarcaba cada sillar sería el siguiente:

Hilada $3^{a}$. [3a: 6]. 3b: [1]+7. 3c: 14. [3d: 14].

Hilada 4${ }^{a}$. [4a: 10]. 4b: [4]+15 (dos letras, fundidas). [4c:18]. 4d: 20. 4e: 7.

3: [Hoc sign]o tuetur pius. Hoc ${ }^{32}$ signo ui[ncitur inimicus]. I

4: [Signum salutis p]one Domine in fonte $\left[\right.$ isto $^{33}$ ut non permittas] introire angelum percutientem. /

"Por este signo es protegido el piadoso. Por este signo es vencido el enemigo". "Pon, Señor, el signo de la salvación en esta fuente, para que no permitas que entre el ángel golpeador”.

El texto figura idéntico en el epígrafe llamado de "la cruz de las puertas"34, salvo por la divergencia debida al tipo de monumento (ianuis istis).

\subsection{A los lados del arco}

Hemos dicho que creemos que el tercer epígrafe comenzaba inmediatamente a continuación de los anteriores, en la hilada quinta, que sufrió la sustitución de sillares ${ }^{35}$. Hoy

\footnotetext{
30 En la transcripción, al abandonar las capitales de los epígrafes, pasamos $V$ a $u$; las resoluciones de abreviaturas aparecen entre paréntesis; marcamos la subsanación de lagunas con corchetes que encierran cursivas. Las partes aún legibles figuran en formato normal.

31 Cuando el texto está perdido o incluso las piedras han sido sustituidas, normalmente no podemos saber si se han fusionado o abreviado letras (pero véase la nota 40). Los caracteres fundidos se cuentan como uno, y no se computa el signo de abreviación.

32 En algunas versiones del texto, esta segunda aparición de signo lleva in delante (por ejemplo, en la miniatura del Antifonario de León, fol. 5v, y del Beato de Valcavado, 1v; fotografías en MArTín BARBA, "La Cruz de Oviedo", p. 47). García de CASTRO VAldés, Arqueología cristiana ..., p. 91, propone la restitución [in] hoc signo para ambos sintagmas. Aunque aparentemente existe espacio libre para la preposición, el hoc conservado está cerrado a la izquierda por su cartela epigráfica, y más a la izquierda se encuentra el cierre correspondiente a ...pius. Puede verse la fotografía del sillar de la hilada tercera en el apartado segundo.

33 Miguel Vigil, Asturias monumental..., vol. 1, pág. 183, y García de Castro Valdés, Arqueología cristiana..., p. 91, prefirieron reconstruir [ista]: en efecto, es habitual el género femenino de fons en época medieval. Precisamente el Liber Ordinum Episcopal ofrece ejemplos con el género masculino clásico, y nosotros lo mantenemos aquí por convención. Había hecho lo mismo Diego SAntos, Inscripciones medievales de Asturias, p. 105.

34 Véase la nota 23.

35 Los dos sillares exteriores de cada jamba de esa hilada, uno corto y otro largo, no pueden conservar texto, porque no son originales, como confirma la petrología: Mateos Redondo, Valdeón MenéndeZ y Rojo
} 
solamente vemos huellas de letras desde la sexta, jamba sur, que, recordamos, es la izquierda para el observador (A). El orden de lectura era de arriba abajo, primero por el lado de la jamba A, y luego por la B. En A se grabó el epígrafe desde la hilada quinta a la decimocuarta; en $\mathrm{B}$, también desde la quinta, pero creemos haber vislumbrado texto en la decimosexta ${ }^{36}$ y no en la anterior.

El texto ensalza el poder del agua y su valor como instrumento de la providencia divina.

No solo era apto para dar lustre a una fuente, sino como refuerzo de la ideología que animaba al reino asturiano: la salvación de los israelitas y la ruina de los egipcios en el mar Rojo servían de trasunto a la lucha del pueblo cristiano contra los musulmanes; David, Moisés, entre otros, eran modelos para sus reyes ${ }^{37}$.

Hemos restituido el texto perdido de la Foncalada básicamente con la versión del Liber Ordinum Episcopal ${ }^{38}$, introduciendo ciertos retoques inspirados en las partes legibles en el monumento, o en el conocimiento del latín que podríamos llamar "áulico" del período asturiano, más estable y culto de lo que suele pensarse. A pesar del escaso texto superviviente, se descubren muestras elocuentes de cuidado gráfico: quae (A 7-2), [l]auas (A 14-2), [la] uaris (A 14-3), que contrastan con sus paralelos en los Ordines (que, labas, labaris). Es también destacable la conservación de la forma culta del prefijo en de[me]rgi[s] (A 12-2/13-1), frente a dimergis.

Partiendo de las letras conservadas y de la observación de que se graban de media unos doce caracteres por línea, aportamos una posible distribución de las letras por sillares, incluso de las grabadas en cada renglón ${ }^{39}$.

\footnotetext{
Álvarez, en "Piedras de construcción de la fuente prerrománica de Foncalada...", p. 116, señalan en la figura 9 el material calizo de los dos sillares exteriores de A y B 5 (y del exterior de B 6). La fuente se construyó básicamente con arenisca.

Para que el epígrafe se hubiera iniciado en la hilada sexta, el sillar exterior de A 6 habría tenido que acoger entre 45 y 53 letras, y el de B 6, entre 48 y 52 . Las cifras menores responderían al uso de abreviaturas, que son escasas en el texto conservado. Es cierto que los sillares de la hilada sexta son alargados, pero haberlos grabado enteros hubiera violado, tanto los márgenes verticales del campo epigráfico que se observan en ambas jambas (además, el texto no invade la altura de las dovelas), como el número habitual de caracteres por línea (entre 11 y 14).

36 Según indicábamos en la nota 14 , las hiladas $15^{\mathrm{a}}-16^{\mathrm{a}}$ no eran visibles en la época en que Vigil dibujó la fuente; en las fotografías de principios del siglo XX aún están ocultas. Parecen haberse liberado de nuevo en el curso de la intervención de 1959-1961: en las imágenes posteriores a esa fecha ya se ven dieciséis hiladas. Puede confrontarse el alzado de Miguel Vigit, Asturias monumental..., vol. 2, lám. K 2, con los de la fuente en su estado actual, en Arias Páramo, San Tirso, Foncalada y Santa María de Bendones..., pp. 47-49.

37 El episodio del mar Rojo es aducido también en las dos versiones de la Crónica de Alfonso III, 10 (edición en Gil Fernández, Moralejo Álvarez y Ruiz de la Peña Solar, Crónicas asturianas, pp. 128-129). David era uno de los protagonistas de los pasajes que inspiraron la antífona adaptada para la inscripción de la hilada cuarta, según hemos visto en la nota 21. En el texto de la oración figura Moisés, que hizo brotar el agua de la peña: Ex 17,6; Nm 20,11. En el testamentum Adefonsi regis, Alfonso II es equiparado a Jacob. Cf. García de Castro Valdés, "Notas sobre teología política...”, p. 160.

38 En contra de la norma clásica, utópica en estos dos casos, hemos aceptado las formas Hebreorum y rupis.

39 Las hiladas se separan con una barra oblicua doble; con una simple, las líneas de las piedras. Entre sus propuestas, Vigil atinó en cuatro caracteres que, por lo menos para nosotros, no son visibles, y que se marcan con un subrayado.
} 
Jamba sur. [A 5: 12/12]. [A 6: 13/1340]. A 7: 12/13. [A8: 11/12]. [A 9: 12/13]. A 10: $[12] /[6]+7$. A 11: $[12] / 3+[1]+2+[5]$. A 12: $[4]+1+[3]+4 / 6+[1]+5$. A 13: $[2]+3+[6] /[12] /[9]+2+[2]$. A 14: $[4]+4+[2] /[6]+6 /[8]+3+[2]$.

Jamba norte. [B 5: 13/12]. [B 6: 13/14]. B 7: [2]+10/[2]+10. [B 8: 12/11]. B 9: $1+[1]+9 /[2]+9$. B 10: $[5]+3+[1]+2+[1]+1 /[11]$. B 11: $11 /[2]+6+[2]+3+[1]$. [B12: 12/13/11]. B 13: $[12] /[1]+10 /[5]+1+[3]+4$.

La disposición del texto en los sillares siguientes plantea mayores problemas. Creemos que en B 14 se grabaron tres líneas de letras con una posible secuencia [B 14: 14/14/13]. Si el texto hubiera terminado de grabarse en B 14, se hubiese salvado la simetría con la jamba $\mathrm{A}^{41}$, pues no vemos en el sillar B 15 huellas de texto por estar cubierto de poros que, si son antiguos, hubieran exigido un buen desbaste del frente para posibilitar la incisión de las letras. El análisis petrológico atestigua que es del mismo tipo que los contiguos: la arenisca gris que fue empleada mayoritariamente para la construcción de la fachada este ${ }^{42}$. Pero nos parece entrever en B 16 por lo menos dos caracteres, $A S$, que coinciden con el final de la breve sección siguiente de la bendición del agua. Así pues, en ese último sillar de B podrían haberse grabado [13]/[13]/[12]+2.

El texto inciso en la fachada este de la fuente representa menos de la mitad de la oración que contienen los Libri Ordinum, pero la parte elegida se grabó íntegra.

A ${ }^{5}$ [Sanctificare / per uerbum Dei // ${ }^{6}$ unda caelestis; / s(an)c(t)ificare, aqua]

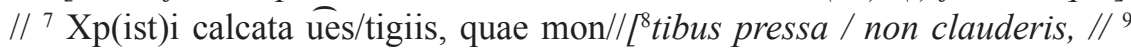
quae scopulis / inlisa non fran//10 geris, quae ter/ris dif]fusa non // ${ }^{11}$ [deficis. Tu sus/]tin[e]s a[ridam, $/ /{ }^{12}$ port] a $[s$ mo]ntiu[(m)] / ponder[a], nec de//13 [me] rgi[s. Tu cae/lorum uertice / contineri] $\underline{\underline{s}} \underline{c}\left[\mathrm{ir} / /{ }^{14} \mathrm{cumf}\right] \underline{\mathrm{u}} \mathrm{sa} \mathrm{p}[\mathrm{er} / \mathrm{totum}, \mathrm{l}]$ auas om[/nia nec la] uar[is.] //

B ${ }^{5}$ [Tu fugientibus / populis Hebre//6 orum in glaciem / durata constrin// ge] ris. Tu rursu(m) / [sa]lsis resolu//[ ${ }^{8}$ ta uerticibus / Nili accolas] // ${ }^{9} \mathrm{p}[\mathrm{e}] \mathrm{rdis}$, et hos/[ti]lem globum // ${ }^{10}$ [freto] seu[i]en[t]e / [persequeris.] // ${ }^{11}$ Vna eademque / [es:] salus f[id] eli $\left[u(m) / /{ }^{12}\right.$ et ultio crimino/sis. Te per Moy/sen percussa // ${ }^{13}$ rupis euomuit, / n] ec abdita ca[/utibu]s [la]tere // ${ }^{14}$ [potuisti, quu(m) mai/estatis imperio / iussa prodires. // ${ }^{16} \mathrm{Tu}$, gestata nubi/bus, imbre iucun/do arua fecund] as.

\footnotetext{
40 El número máximo sería 16, pero si se abrevia del modo habitual en la época, $s(a n) c(t) i f i c a r e$ (el término ha salido en el sillar anterior), daría 13 caracteres, la misma cifra que la línea superior.

41 Con la salvedad de la diferencia en el número de líneas asignado a la hilada 12.

42 Así lo indica la figura 9 del trabajo de Mateos Redondo, Valdeón Menéndez y Rojo Álvarez, "Piedras de construcción...", p. 116.
} 
En el aparato crítico damos acogida a las variantes de todo tipo del Liber Ordinum Episcopal y del Sacerdotal ${ }^{43}$, y solamente a las discrepancias gramaticales y léxicas de las otras versiones citadas de la bendición.

A 6 caelestis ] celestis Férotin, Janini ${ }^{1} \| 7$ quae ] que Férotin, Janini ${ }^{1-2} \|$ 9 quae ] que Férotin, Janini ${ }^{l-2} \mid$ scopulis ] scopolis cod. Férotin, scopolis Janini $^{l-2} \| 9$ quae ] que Férotin, Janini ${ }^{l-2} \| 10$ quae ] que Férotin, Janini ${ }^{l-2}$ | diffusa ] infusa Mercati || 12-13 demergis ] dimergis cod. Férotin; dimergis Janini ${ }^{1-2}$; demergeris Pontificale $\| 13$ caelorum ] celorum Férotin, Janini ${ }^{1-2} \|$ 14 lauas ] labas cod. Férotin, labas Janini ${ }^{1-2}$ | lauaris ] labaris cod. Férotin, labaris Janini ${ }^{1-2}$. B 5-6 hebreorum ] ebreorum Férotin, Janini ${ }^{l-2} \| 6$ glaciem ] glacies Mercati, glaciem in apparatu; molem Martène, Ménard, Pontificale | durata ] coagolata Mercati || 6-7 constringeris ] constricta es Pontificale || 7 rursum ] rursus Férotin, Janini ${ }^{1-2} \mid$ salsis ] salis Férotin, Janini ${ }^{1-2}$; falsis Martène; altis Mercati; || 8 uerticibus ] uorticibus Ménard, Pontificale |accolas ] acolas Janini ${ }^{1} \| 9$ hostilem ] ostilem Janini ${ }^{l}$; hostili Mercati | globum ] globo Mercati $\| 11$ es ] om. Mercati | fidelium ] fidelibus Janini ${ }^{l}$, Martène, Ménard, Pontificale $\| 12$ percussa ] percussura Janini ${ }^{1} \| 13$ rupis ] rupes, rupis cod. Férotin | latere ] inlatere Janini ${ }^{I} \| 14$ potuisti ] potuissti Janini ${ }^{1} \mid$ maiestatis ] magestatis Janini ${ }^{1} \| 16$ arua ] arba cod. Férotin, arba Janini ${ }^{1-2}$.

"Santificada seas por la palabra de Dios, ola celeste; santificada seas, agua hollada por las plantas de Cristo; los montes que te ciñen no te encierran; los escollos que te golpean no te quiebran; extendida por las tierras, no te extingues. Tú sostienes la tierra firme, soportas el peso de los montes, y no te hundes. Esparcida por todo en torno tuyo, te abarca el vértice de los cielos; lavas todas las cosas y no eres lavada. Endurecida en forma de hielo, tú te comprimes para el pueblo fugitivo de los hebreos. Por el contrario, disuelta en torbellinos salados, pierdes a los habitantes del Nilo y persigues a la tropa enemiga con un mar alborotado. Eres única e igualmente salvación de los fieles y castigo para los culpables. La peña golpeada por Moisés te expulsó $y$, aunque estabas retirada, no pudiste mantenerte oculta en las rocas, ya que saliste obligada por el mandato de la Majestad. Transportada por las nubes, tú fecundas los campos con la grata lluvia" ${ }^{4}$.

\footnotetext{
43 La versión del Sacerdotal, denominada en el aparato Janini ${ }^{1}$, es lingüísticamente más vulgar que la del Episcopal $\left(\right.$ Janini $\left.^{2}\right)$.

${ }_{44}$ La última frase corresponde al fragmento tu... fecundas, que con cautela hemos supuesto para B 16.
} 


\section{Valor de la inscripción}

Que en la Foncalada se hubiera grabado la bendición de una fuente bautismal puede llevar a la hipótesis de que el monumento, con un estanque apto para la inmersión ${ }^{45}$, hubiese servido para el bautismo. Sin embargo, está alejado de la basílica de San Salvador, cuyo baptisterio ${ }^{46}$ tuvo como manantial una fuente denominada elocuentemente “del Paraíso". Parece más prudente asumir que, con esta loa del poder de las aguas, se hubiera pretendido la sacralización cristiana de una corriente ya utilizada, quizá desde antiguo, como medicinal. Además, las alusiones bíblicas que contiene, por los paralelos que se podían establecer, servían bien, según hemos dicho, a la ideología de un reino cristiano empeñado en una contienda con el Islam, con la alianza entre trono y altar como uno de sus pilares.

La reconstrucción del epígrafe corrobora el influjo de las obras litúrgicas, en concreto de los Ordines, en la producción escrita del período asturiano. Más valioso hubiera sido descubrir en las letras desgastadas de la Foncalada una obra original pero, precisamente gracias a que no lo es, ha podido identificarse el texto: los fragmentos legibles a los lados del arco siguen la bendición conocida, afín sobre todo a la versión del Liber Ordinum Episcopalis, de la que a nuestro juicio depende directamente la oración incisa en la Foncalada.

No carece de interés el hecho de que, a pesar de los escasos restos conservados, se descubran en esta versión de la bendición variantes textuales con respecto a las otras dos muestras hispanas de la oración (rursum [sa]lsis, B 7, frente a rursus salis); también se distingue la redacción ovetense por su cuidado desde el punto de vista de la lengua latina (representación de -ae-, notación clásica de - $u$-; conservación de $d e-$ ), debido a un modelo - $\mathrm{O}$ a un redactor del borrador para los epígrafes - de nivel apreciable. Además, la copia de la Foncalada es más antigua que los manuscritos que sirven de base para la edición de los Libri Ordinum ${ }^{47}$.

Debe resaltarse el cuidado que se ha puesto en la copia de la inscripción, que denota un plan y una perspectiva generales, como reflejan sus pautas y márgenes, señalados en las piedras con marcas en bastantes casos aún visibles, y concebidos con notable regularidad para delimitar el campo epigráfico. Los fragmentos conservados han permitido además postular una distribución equilibrada del número de caracteres por línea. También se graduó el tamaño de las letras. Se ha buscado la simetría en la disposición del conjunto epigráfico, presidido por la cruz; solamente se ve empañada en el sillar final de la jamba norte, si hemos acertado al defender que haya acogido caracteres.

\footnotetext{
45 Se refiere a su posible profundidad Ríos GonzÁlez, "Arquitectura del agua en la Alta Edad Media...", pp. 532-533; "La fuente de Foncalada: paralelos...", p. 273.

46 Estaba situado al noroeste de la iglesia de Santa María del Rey Casto, vecina de San Salvador: GARCía de Castro Valdés y Ríos González, "El origen de Oviedo", pp. 58-59.

47 El manuscrito S 4 del Episcopal es de 1052 y el A 56 ha sido datado a fines del s. X (datos en JANINI, Liber Ordinum Episcopal, pp. 23 y 28). El manuscrito del Sacerdotal (S3) es de 1039 (JANINI, Liber Ordinum Sacerdotal, p. 14).
} 
La identificación de nuevas letras permite enriquecer el catálogo paleográfico que proporcionan las escrituras ${ }^{48}$, que es uno de los elementos auxiliares para la datación aproximada del monumento. Ocasionalmente se observa variedad de trazos para una misma letra, lo que puede merecer una atención más específica.

Aunque falten referencias al monarca y a la fecha de erección ${ }^{49}$, la cruz y las inscripciones que campean sobre el arco, con numerosos paralelos en lápidas y piezas de orfebrería de la época, garantizan el patrocinio regio de una obra a la que se consagró un gran empeño ${ }^{50}$. Pero la protección religiosa y el empaque dispensados al complejo no evitaron la degradación de sus usos: como mínimo desde mitad del siglo XIII, las aguas de la fuente se emplearon en labores de curtido de pieles $^{51}$, y el monumento se utilizó como lavadero incluso en el siglo XX. Ni siquiera en la actualidad recibe un trato digno de su mérito ${ }^{52}$.

\section{Bibliografía citada}

Ambrosi Mediolanensis, Expositio Evangelii secundum Lucam, Sancti Ambrosii Mediolanensis episcopi opera omnia, tomi primi pars posterior, ed. Jacques-Paul Migne, Patrologia Latina, apud J.-P. Migne editorem, Parisiis, 1845, vol. 15, col. 1815.

Arias Páramo, Lorenzo, San Tirso, Foncalada y Santa María de Bendones (Guías del perrománico asturiano), Nobel, Oviedo, 2009.

Biblia sacra iuxta vulgatam versionem, eds. Robert Weber y Roger Gryson, Deutsche Bibelgesellschaft, Stuttgart, 2007, $5^{\mathrm{a}}$ ed.

\footnotetext{
48 García de CASTRo VAldÉs ofrece, como anexo a su obra Arqueología cristiana ..., una tabla con las letras de los epígrafes altomedievales asturianos según su estado de conocimiento en la época de la publicación. 49 Es complicado postular una inscripción con esas informaciones: solamente quedaría libre la segunda hilada (bajo la cruz) para haberlo grabado. El primer sillar alargado por la izquierda contiene un trazo horizontal prolongado, semejante a una pauta, pero soy incapaz de distinguir letras en las incisiones de la piedra (a este respecto, parecen insinuarse grabados ornamentales en algunos sillares). Por otra parte, las piedras A 15-16, donde no se reconocen caracteres, no debían recibir un texto de otro asunto que hubiera interrumpido el decurso de la bendición del agua. La inscripción llamada "de las puertas", cuyo contenido hemos señalado que es prácticamente idéntico al de las hiladas 3-4 de la Foncalada, también carece de toda referencia a fecha o impulsor.

50 La construcción exigió el acarreo del material desde un punto distante. Mateos Redondo, Valdeón Menéndez y Rojo Álvarez, en "Piedras de construcción...", p. 118, indican que la fuente se edificó mayoritariamente con piedra arenisca jurásica de la formación llamada Lastres, que aflora en tramos costeros entre La Providencia (Gijón) y Arra (Ribadesella). En otro artículo estudian el mortero original y los cinco de las restauraciones, y destacan la mayor resistencia del primero: Rojo ÁlvareZ, Mateos Redondo y VALDEóN MENÉNDEZ, "Caracterización petrológica de los morteros de la fuente prerrománica de Foncalada...", pp. $166-167$ y $174-175$

51 Ríos GonzÁlez, "Excavación arqueológica...”, pp. 187-189. García de CAstro Valdés y Ríos González, "El origen de Oviedo", p. 100.

52 Accesible a todas horas, sin vigilancia de ninguna clase, sirve de área de expansión a dos locales nocturnos, una cervecería y un karaoke, con las consecuencias y los riesgos que cualquiera se puede imaginar.
} 
Borge Cordovilla, Francisco José, "La Fuente de Foncalada (Oviedo): aplicación de métodos gráficos e infográficos de análisis compositivo y metrológico a la formulación de una hipótesis de anastilosis virtual del monumento", Virtual Archaeology Review, 2, 3 (2011), pp. 165-168.

Borge Cordovilla, Francisco José, "La fuente de Foncalada", Mirabilia Ovetensia (http://www.mirabiliaovetensia.com/Fuente_Foncalada.html), [12-I-2018].

Brou, Louis y Vives, José, Antifonario visigótico mozárabe de la catedral de León, Consejo Superior de Investigaciones Científicas, Barcelona-Madrid, 1959.

Díaz y Díaz, Manuel C., Códices visigóticos en la monarquía leonesa, Centro de Estudios e Investigación San Isidoro, León, 1983.

Diego Santos, Francisco, Inscripciones medievales de Asturias, Consejería de Educación, Cultura, Deportes y Juventud, Oviedo, 1994.

Estrada García, Rogelio y Ríos González, Sergio, "Excavaciones arqueológicas en la plaza de Foncalada (Oviedo), 1991-1994”, Excavaciones arqueológicas en Asturias, 1991-94, Servicio de publicaciones de la Consejería de Cultura, Oviedo, 1995, pp. 137-146.

FÉrotin, Marius, Le Liber Ordinum en usage dans l'église wisigothique et mozarabe d'Espagne du cinquième à onzième siècle, Firmin-Didot et C Carís, 1904.

García De Castro Valdés, César, Arqueología cristiana de la Alta Edad Media en Asturias, Real Instituto de Estudios Asturianos, Oviedo, 1995.

García De Castro Valdés, César, "La Cruz de la Victoria de la Cámara Santa de la Catedral de Oviedo como ejemplo de la confección de relicarios en el reino de Asturias", Codex Aquilarensis, 32 (2016), pp. 27-56.

García De Castro Valdés, César, "Notas sobre teología política en el reino de Asturias: la inscripción del altar de Santa María de Naranco (Oviedo) y el testamento de Alfonso II", Arqueología y territorio medieval, 10, 1 (2003), pp. 137-170.

García De Castro Valdés, César, (ed.), Signum Salutis. Cruces de orfebrería de los siglos $V$ al XII, Consejería de Cultura y Turismo del Principado de Asturias-KRK ediciones, Oviedo, 2008.

García De Castro Valdés, César y Ríos González, Sergio, "El origen de Oviedo", Anejos de Nailos. Estudios interdisciplinares de arqueología, 3 (2016), pp. 31-199.

Gil Fernández, Juan, Moralejo Álvarez, José Luis, y Ruiz de la Peña Solar, Juan Ignacio, Crónicas asturianas, Universidad de Oviedo, Oviedo, 1985.

GREGORII papae, cognomento MAGNI, Liber sacramentorum. Opera omnia, tomus quartus, ed. Jacques-Paul Migne, Patrologia Latina, apud J.-P. Migne editorem, Parisiis, 1862, vol. 78, cols. 153-154.

JaninI, José, Liber Ordinum Episcopal (cód. Silos, Arch. monástico, 4), Abadía de Silos, Silos, 1991. 
JAnInI, José, Liber Ordinum Sacerdotal (cód. Silos, Arch. monástico, 3), Abadía de Silos, Silos, 1981.

Martene, Edmundus, De antiquis ecclesiae ritibus libri, Typis Joannis Baptistae de la Bry, Antuerpiae, MDCCXXXVI, ed. secunda, t. II.

Martín Barba, José Julio, "La Cruz de Oviedo", Revista Digital de Iconografía Medieval, 8, 15 (2016), pp. 27-50.

Mateos Redondo, Félix J., Valdeón Menéndez, Luis y Rojo Álvarez, Araceli, "Piedras de construcción de la fuente prerrománica de Foncalada : tipos y origen", Trabajos de Geología, 24 (2004), pp. 107-118.

MenÉndez PidAl, Gonzalo, "El lábaro primitivo de la Reconquista. Cruces asturianas y cruces visigodas”, Boletín de la Real Academia de la Historia, 136, 2 (1955), pp. 7-28.

MENÉNDEZ PIDAL, Luis, "Influencias y expansión de la arquitectura prerrománica asturiana en alguna de sus manifestaciones", Symposium sobre cultura asturiana de la Alta Edad Media. Septiembre de 1961, Excmo. Ayuntamiento de Oviedo, Oviedo, 1964, pp. 59-98.

Mercati, Giovanni, Antiche reliquie liturgiche ambrosiane e romane, con un excursus sui frammenti dogmatici ariani del Mai, Tipografia Vaticana, Roma, 1902.

Miguel Vigil, Ciríaco, Asturias monumental, epigráfica y diplomática. Datos para la historia de la provincia, Imprenta del Hospicio Provincial, Oviedo, 1887, 2 vols.

Pontificale Romanum Clementis VIII pont. max. iussu restitutum atque editum, apud Iacobum Lunam, Romae, 1595, pp. 319-320.

Ríos GonzÁlez, Sergio, "Arquitectura del agua en la Alta Edad Media. El ejemplo de Foncalada (Oviedo), Termalismo antiguo (I Congreso peninsular. Actas), María Jesús Pérex Agorreta (ed.), UNED, Madrid, 1997, pp. 529-533.

Ríos GonzÁLEz, Sergio, “Excavación arqueológica en la Foncalada: 1991-1995”, La intervención en la arquitectura prerrománica asturiana, Jorge Hevia Blanco (comp.), Universidad de Oviedo, Oviedo, 1997, pp. 183-189.

Ríos González, Sergio, "La fuente de Foncalada: paralelos técnicos, formales y funcionales", Zephyrus, 52 (1999), pp. 261-278.

Ríos González, Sergio, Estrada García, Rogelio y Chao Arana, Javier, "La fuente de Foncalada (Oviedo)", Boletín del Real Instituto de Estudios Asturianos, 144 (1994), pp. 399-422.

Rodríguez DíAz, Elena E., El libro de la "Regla Colorada”. Estudio y edición, Real Instituto de Estudios Asturianos, Oviedo, 1995.

Rojo Álvarez, Araceli, Mateos Redondo, Félix J. y Valdeón Menéndez, Luis, "Caracterización petrológica de los morteros de la fuente prerrománica de Foncalada, Oviedo", Trabajos de Geología, 24 (2004), pp. 165-175.

Selgas, Fortunato de, Monumentos ovetenses del siglo IX, Nueva imprenta de San Francisco de Sales, Madrid, 1908 (Colección facsimilar asturiana, Silverio Cañada editor, Gijón, 1991). 


\section{Anexo. Disposición hipotética de los epígrafes de la Foncalada ${ }^{53}$}

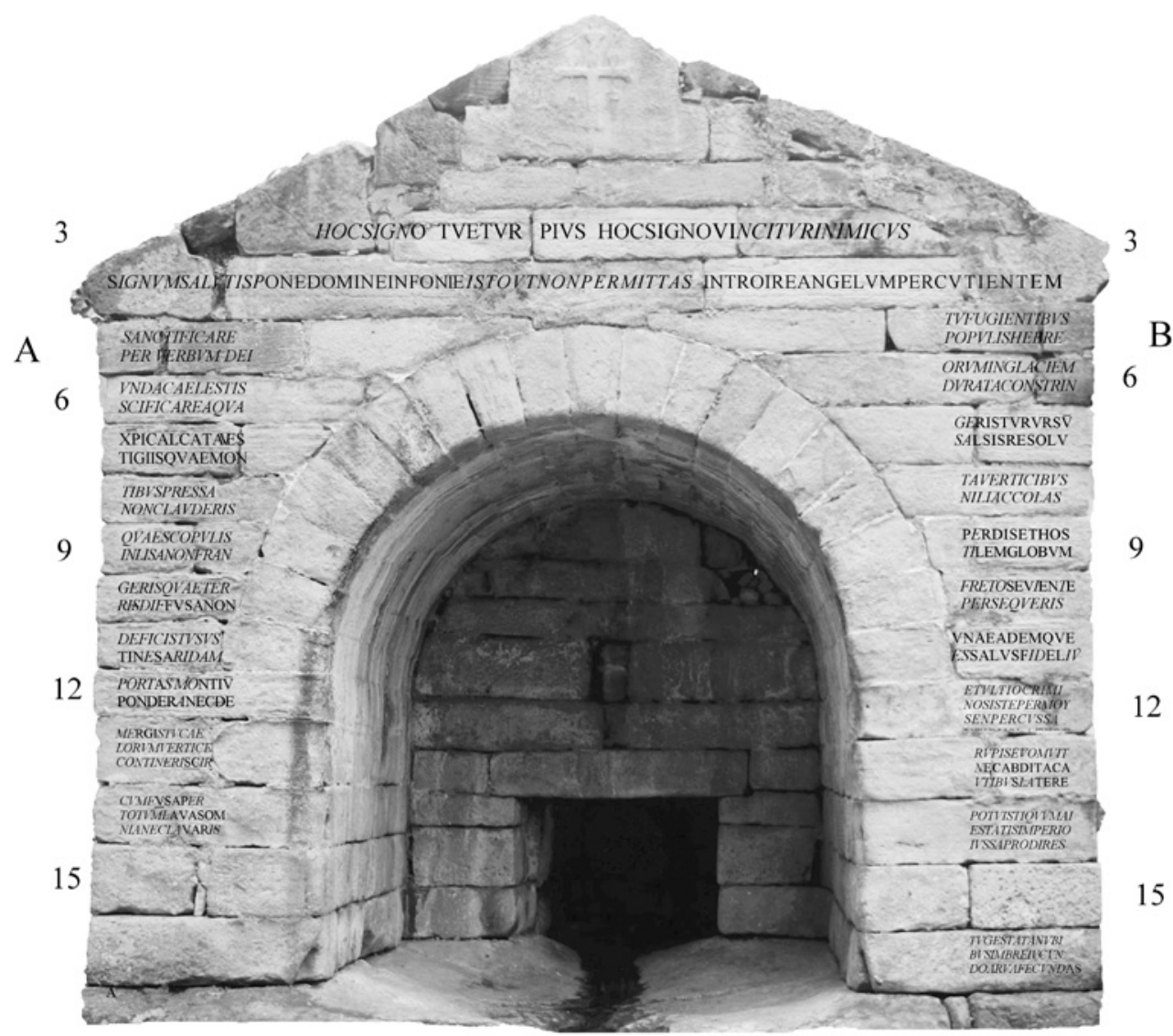

53 En letra común, caracteres legibles; en cursiva, las suplencias; subrayadas, letras aún vistas por Ciríaco Miguel Vigil. 